\title{
Undisclosed methyldibromo glutaronitrile causing allergic contact dermatitis in a NSAID cream
}

\author{
Cristina Amaro ${ }^{1}$, Mariana Cravo² ${ }^{2}$ Cândida Fernandes ${ }^{1}$, Raquel Santos ${ }^{1}$ and Margarida Gonçalo ${ }^{2}$ \\ ${ }^{1}$ Department of Dermatology, Hospital de Curry Cabral, 1069-166 Lisbon, Portugal and ${ }^{2}$ Department of Dermatology, Hospitais da Universidade de Coimbra, \\ Coimbra, Portugal \\ doi:10.1111/j.1600-0536.2012.02091.x
}

Key words: allergic contact dermatitis; Euxyl ${ }^{\circledR}$ K 400; methyldibromo glutaronitrile; preservative; topical drug.

The allergenicity of methyldibromo glutaronitrile (MD BGN) (1,2-dibromo-2,4-dicyanobutane) is well recognized, both in occupational and in non-occupational settings (1). Used as a preservative, alone or in combination with phenoxyethanol (Euxyl ${ }^{\circledR} \mathrm{K} 400$ ), in metalworking fluids, cosmetics, adhesives, and moist toilet tissues, it was identified as an increasingly important allergen soon after its launch in the 1980s $(2,3)$. The increasing rates of sensitization to this preservative prompted the European Commission to restrict its use, first in leave-on (4), and later also in rinse-off cosmetics (5). Despite these recommendations, which have shown to be successful in reducing the prevalence of contact allergy to this molecule (3), some important consumer products, such as topical drugs, are still not subject to regulatory intervention.

We report two cases of allergic contact dermatitis caused by MDBGN in a topical non-steroidal antiinflammatory cream.

\section{Patients}

\section{Case Report 1}

In April 2006, a 53-year-old male electrician presented with an extensive bullous eczema, initially localized to one leg, knee, and arm, followed by a widespread eczematous reaction. On the days before, the patient reported having applied Reumoxican ${ }^{\circledR}$ cream (Medinfar Laboratories, Portugal), a topical non-steroidal anti-inflammatory cream containing piroxicam. He also had used, for longer periods, Reumon gel ${ }^{\circledR}$ (Bial Laboratories, Portugal), a nonsteroidal anti-inflammatory gel containing etofenamate. Systemic steroids were needed to control the reaction.

Correspondence: Cristina Amaro, Department of Dermatology, Hospital de Curry Cabral, Rua da Beneficência, no. 8, 1069-166 Lisbon, Portugal. E-mail: cristinacamaro@sapo.pt

Conflicts of interest: The authors have declared no conflicts.

\section{Case Report 2}

In November 2008, a 77-year-old female presented with a 2-week history of eczematous bullous lesions affecting both hands and the lower back, after having applied Reumoxican ${ }^{\circledR}$ cream (Medinfar Laboratories) and a topical antihistamine cream containing promethazine (Fenergan ${ }^{\circledR}$; Vitória Laboratories, Amadora, Portugal). The patient was treated with topical corticosteroids, with complete remission of the dermatitis in a few days.

\section{Patch Tests}

Patch testing was performed using Finn Chambers ${ }^{\circledR}$ and according to the International Contact Dermatitis Research Group criteria, with the Portuguese baseline series. Photopatch tests were performed in duplicate with a non-steroidal anti-inflammatory drug (NSAID) series or a more extended photopatch test series and patients' own products, with irradiation of one set at D2 with $5 \mathrm{~J} / \mathrm{cm}^{2}$ ultraviolet A (UVA). Both patients reacted to MDBGN $0.3 \%$ pet. $\left(\right.$ Trolab $^{\circledR}$ ) $[+++$, patient 1 (Fig. 1a), and ++ , patient 2] and to Reumoxican ${ }^{\circledR}$ cream (Fig. 1b), in both non-irradiated and irradiated areas, with identical intensity. Piroxicam 10\% pet. (Chemotechnique Diagnostics ${ }^{\circledR}$ ) patch and photopatch testing gave negative results. Patient 2 reacted also to the irradiated Fenergan ${ }^{\circledR}$ cream containing promethazine $(++)$. This patient was further patch-tested with all of the ingredients of Reumoxican ${ }^{\circledR}$ cream, and had a positive reaction $(++)$ to Euxyl ${ }^{\circledR} \mathrm{K} 400$ 1\% pet. (Medinfar Laboratories).

MDBGN and phenoxyethanol were identified in the Reumoxican ${ }^{\circledR}$ labelled ingredients $\left(0.4 \%\right.$ Euxyl ${ }^{\circledR} \mathrm{K} 400$, and therefore $0.08 \%$ MDBGN).

\section{Discussion}

Topical NSAIDs are widely prescribed by family physicians, and are used as over-the-counter drugs for their 

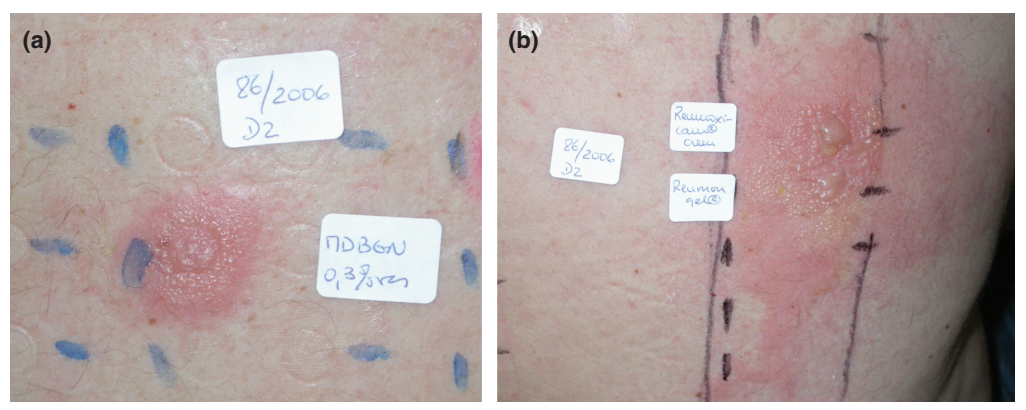

Fig. 1. (a) Positive patch test reaction to methyldibromo glutaronitrile $0.3 \%$ pet. and (b) Reumoxican ${ }^{\circledR}$ cream (case 1). analgesic/anti-inflammatory effects in cream or gel formulations. They have been reported to cause allergic or photoallergic contact dermatitis, particularly from the active ingredients. We report two cases of allergic contact dermatitis resulting from the use of Reumoxican ${ }^{\circledR}$ cream, with negative reactions to the active ingredient piroxicam. Both patients reacted to MDBGN, which was identified as an ingredient of this topical drug.

This broad-spectrum biocide is, indeed, considered to have caused an epidemic of contact allergy in Europe, and was therefore banned from cosmetics and toiletries, owing to high sensitization rates $(3,6)$.

The otherwise successfulEU legislation does not include topical drugs, which still occasionally contain this preservative. Moreover, unlike the situation with cosmetics, full labelling of ingredients is not compulsory for topical drugs and medical devices in some European countries. We stress the urgent need to extend regulatory interventions to topically applied medications, so that they can be more safely used.

\section{References}

1 Zachariae C, Johansen J D, Rastogi S C, Menné T. Allergic contact dermatitis from methyldibromo glutaronitrile - clinical cases from 2003. Contact Dermatitis 2005: 52: $6-8$.

2 Heratizadeh A, Killig C, Worm M et al. Quantitative repeated open application testing with a rinse-off product in methyldibromo glutaronitrile-sensitive patients: results of the IVDK. Contact Dermatitis 2010: 62: 330-337.
3 Johansen J D, Veien N, Laurberg G et al. Decreasing trends in methyldibromo glutaronitrile contact allergy - following regulatory intervention. Contact Dermatitis 2008: 59: 48-51.

4 Commission of the European Communities. Commission directive 2003/83/EC of 24 September 2003. Off J Eur Union 2003: L238: 23-27.

5 Commission of the European Communities. Commission directive 2007/17/EC of 22
March 2007. Off J Eur Union 2007: L82: 27-30.

6 Johansen J D, Veien N K, Laurberg G, Kaaber K, Thormann J, Lauritzen M, Avnstorp C. Contact allergy to methyldibromo glutaronitrile - data from a 'front line' network. Contact Dermatitis 2005: 52: 138-141. 